\title{
Final pressure setting of programmable valve in ventriculo-atrial shunt for idiopathic normal pressure hydrocephalus
}

Kiyoshi Takagi

From Hydrocephalus 2015

Banff, Canada. 18-21 September 2015

\section{Introduction}

A quick reference table for setting programmable pressure valves in patients with idiopathic normal pressure hydrocephalus (iNPH) has been proposed for ventriculoperitoneal shunt (VP shunt) (Miyake et al. Neurol Med Chir (Tokyo) 48, 2008). Recommended pressure has strong correlation with body mass index (BMI). However, little is known about the ideal pressure setting for ventriculo-atrial shunt (VA shunt). The purpose of this paper is to show the final pressure setting in the iNPH patients with good outcome received VA shunts and to investigate the correlation between the final pressure setting and preoperative factors.

\section{Patients and Methods}

Eighty-four iNPH patients with good outcome (improved modified Rankin Scale, improved mini-mental state examination over 3, cease of urinary incontinence, or reduced care-giver's burden without improvement of modified Rankin Scale) at one year after VA shunts using programmable valve with anti-siphon device were the candidates of this study. Correlations between final pressure setting and BMI, body length, body weight, and preoperative cerebrospinal fluid (CSF) pressure measured by lumbar tap were investigated. Data were shown in mean $+/-$ SD and statistically analyzed by calculating Pearson productmoment correlation coefficients and the significant level was set at $\mathrm{p}$ less than 0.05 .

\section{Results}

Mean age was $77.6+/-6.1$ years old (male : female $=48$ : 36). Mean body length, body weight, and BMI were
$157.2+/-8.8 \mathrm{~cm}, 54.1+/-10.8 \mathrm{~kg}$, and $21.8+/-3.3$ respectively. Preoperative CSF pressure was $118.9+/-34.2$ $\mathrm{mmH} 2 \mathrm{O}$. The mean initial valve pressure setting was $126.3+/-17.6 \mathrm{mmH} 2 \mathrm{O}$ (median $=120 \mathrm{mmH} 2 \mathrm{O}$ ) and the mean final pressure setting was $62.1+/-31.3 \mathrm{mmH} 2 \mathrm{O}$ (median $=55 \mathrm{mmH} 2 \mathrm{O})$. There were no significant correlations between the final pressure setting and $\mathrm{BL}, \mathrm{BW}, \mathrm{BMI}$, and CSF pressure. In 43 cases, final pressures were below $50 \mathrm{mmH} 2 \mathrm{O}$ including 23 cases with the lowest setting of $30 \mathrm{mmH} 2 \mathrm{O}$.

\section{Discussion and conclusion}

This study clearly demonstrated that there were no preoperative determinants for the ideal setting of valve pressure in VA shunt. It also demonstrated that the final setting was unexpectedly low and it suggests the necessity of lower setting valve.

Published: 18 September 2015

doi:10.1186/2045-8118-12-S1-O49

Cite this article as: Takagi: Final pressure setting of programmable valve in ventriculo-atrial shunt for idiopathic normal pressure hydrocephalus. Fluids and Barriers of the CNS 2015 12(Suppl 1):049. 